\title{
基于乡村多功能评价的城市边缘区 “三生”空间划分研究
}

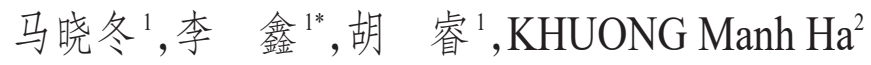

(1. 江苏师范大学地理测绘与城乡规划学院, 江苏 徐州 221116 ;

2. 北江农林大学土地与资源环境学院, 越南 北江 0084240)

\begin{abstract}
摘 要: 城市边缘区乡村多元价值凸显, 迫切需以乡村多功能理论为指导划分 “三生” 空间, 以空间重构促进转型发 展。论文首先从生产、生活与生态功能方面评价城市边缘区多功能时空变化; 其次进行图斑尺度“三生”空间适宜 性评价,两者共同得到基于乡村多功能的“三生”空间适宜性;最后据此设计算法划分“三生”空间。研究发现: 1 城市边缘区乡村休闲娱乐、观光农业等功能显现, 需要重构多功能空间促进转型发展; 2 江苏徐州市铜山区乡村 非农生产与生活功能主要分布在与中心城区较近地区,农业空间主要分布在中心城区远郊外围,生态功能则表现 出高度空间异质性,农业、非农生产与生活功能在提升, 而生态功能则普遍下降; 3 县域“三生”空间划定需多尺度 联合, 既要考虑乡镇尺度多功能差异, 还要体现图斑尺度适宜性, 才能为空间规划提供有意义的借鉴。论文提出的 基于乡村多功能评价的“三生”空间划分可为即将开展的国土空间规划提供科学依据。
\end{abstract}

关 键 词:乡村多功能; 城市边缘区; “三生”空间; 江苏徐州铜山区

乡村多功能理论兴起于 20 世纪 80 年代, 目前 正在世界范围内指导农村转型发展(Stola, 1986; Wilson, 2001; Holmes, 2006)。其主要涵义指乡村 不仅具有农业生产功能, 还具有社会文化、生态调 节、休闲娱乐等功能, 且这些功能价值随工业化与 城镇化深人愈发凸显, 可为乡村发展提供内生动 力, 成为跨越式转型发展的主要路径, 为现阶段中 国乡村振兴与转型重构提供重要理论支持(房艳刚 等, 2015)。下文按“理论一评价一应用”3 个层面简 要梳理中国乡村多功能研究状况, 学者已对乡村多 功能内涵、类型、演进机制与互馈动力等进行了研 究, 但同时指出如何精准选取相关指标表征多功能 是一个重要挑战(刘玉等, 2011; 刘玉等, 2012)。更 多学者对不同尺度的乡村多功能进行评价, 现有文
献中最小评价尺度是乡镇级,在评价方法上基本是 用综合评价法, 即各指标标准化值与权重乘积的累 加。在对多功能评价之后,有研究用 Dagum 基尼系 数分析乡村多功能空间差异及来源(洪惠坤, 2016; 洪惠坤等, 2016), 有些用空间分析方法, 如 Moran's $I$ 指数、重心位移等分析其空间分布特征与变化(李 平星等, 2014), 有些则用空间计量与相关性分析法 识别多功能时空变化的影响因素 (戈大专等, 2018)。在应用层面, 主要是据其进行多功能分区 以指导社会经济的空间布局, 优化土地利用格局, 但通常乡镇为最小评价单元, 故现有文献中多功能 分区多以镇为单元(李智等, 2017; 王婕等, 2018), 对 实施性空间规划借鉴意义有限。

城市边缘区是城乡功能的 “过渡域”与城乡要

收稿日期 : 2019-04-29; 修订日期 : 2019-07-14。

基金项目: 国家自然科学基金项目(41971221); 教育部人文社科项目(19YJCZH089); 江苏高校社科基地项目(2017ZSJD013)。

[Foundation: National Natural Science Foundation of China, No. 41971221; MOE Project of Humanities and Social Sciences, No. 19YJCZH089; Social Science Foundation Project Outside of Jiangsu Provincial Universities, No. 2017ZSJD013. ]

第一作者简介:马晓冬(1971一), 男,江苏徐州人,教授,主要研究方向为乡村地理。E-mail: xiaodgma@163.com *通信作者简介:李金金(1986-), 男,山东临沂人,副教授,主要研究方向为土地利用与空间规划。E-mail: topzcg@126.com X D, Li X, Hu R, et al. 2019. Delineation of "production-living-ecological" space for urban fringe based on rural multifunction evaluation. Progress in Geography, 38(9): 1382-1392. ] DOI: 10.18306/dlkxjz.2019.09.011 
素交流的“接口态”,其土地利用、产业结构与人口 社会等有较强异质性,且处在快速变化状态(Pryor, 1968)。由于中国管理体制的交叉性与边缘性, 城 市边缘区既面临剧烈土地利用变化, 还面临产业结 构迅速变迁与人口非农化、兼业化与流动化导致的 社会空间结构不断重组,从而使该地区呈现出产业 空间混杂化、文化空间碎片化、生态空间无序化等 问题(乔家君等, 2016)。但随着工业化与城镇化发 展, 以及后生产主义开始出现, 正如 Holmes(2006) 所指出, 外部条件变化会使城市边缘区乡村景观的 多功能价值凸显, 农村不再仅是生产空间, 而且呈 现出休闲养生、文化教育、环境保护等多功能, 成为 具有独特文化与景观价值的人居形态(宋志军等, 2012; 刘祖云等, 2018)。因此, 在中国城镇化进人 中后期时, 迫切需以乡村多功能理论为指导对城市 边缘区进行重构, 以实现超越现代化发展范式的跨 越(房艳刚等, 2015)。从2012年党的十八大报告提 出 “三生”空间以来,划分 “三生” 空间成为国土空间 优化基础与空间规划的主要内容(李广东等, 2016)。“三生” 空间旨在形成多功能相互协调之格 局, 属于多功能分区类型之一, 故天然需要乡村多 功能理论作为指导(黄金川等, 2017), 虽然有些基于 图斑尺度的 “三生” 空间划分研究是以多功能理论 为指导, 但未较好融合多功能评价结果, 也未考虑 不同单元对不同功能适宜性的竞争(林娇, 2018; 杨 俊等, 2018)。

综上所述, 在进人城镇化中后期, 迫切需对中 国城市边缘区的乡村多功能进行整合, 打造多元价 值空间, 促进其转型发展(张英男等, 2019); “三生” 空间划分是国土空间优化的重要内容, 天生需要耦 合多功能评价结果(李广东等, 2016)。鉴于此, 本文 以江苏徐州市铜山区为例开展基于乡村多功能评 价的城市边缘区“三生”空间划定研究,一方面拓展 乡村多功能理论的应用深度, 提出一种基于乡村多 功能的县域图斑尺度 “三生” 空间划定法, 另一方面 可优化城市边缘区的土地利用, 为多元价值挖掘与 培育提供空间基础, 为地区转型发展与空间重构提 供科学借鉴。

\section{1 研究区概况、数据与方法}

\section{1 研究区概况}

徐州市铜山区位于江苏省西北部, 坐拥历史名
城徐州,处苏、鲁、皖三省交界处。其最主要空间特 征是围绕了约 $3 / 4$ 个徐州中心城区, 属于典型城市 边缘区,土地利用、产业类型与人口组分等呈现出 典型城市边缘区特征。近年来乡村消费娱乐等多 功能在铜山区强势出现, 成为徐州中心城区休闲体 验的后花园,这一方面促进了农村转型发展, 提高 农民收人; 但另一方面由于缺乏多功能规划应对, 导致这些功能空间碎片化, 品质不高, 同时侵蚀优 质耕地。因此,迫切需要基于乡村多功能评价划定 县域“三生”空间,在国土空间管制前提下引导培育 各类乡村功能。

\section{2 数据来源与处理}

2009 年与 2016 年两期 1:5000 土地利用现状 矢量数据是徐州市自然资源局的 “二调”与变更数 据; 不同乡镇的人口、农民收人、粮食产量、农业机 械水平、工业产值等社会经济数据来自《徐州统计 年鉴》; 其他数据来自于《铜山区环境保护规划》 《铜山区生产力布局规划》等。空间适宜性评价基 于 $50 \mathrm{~m} \times 50 \mathrm{~m}$ 栅格尺度, 而乡村多功能评价基于乡 镇尺度。

\section{3 研究方法}

\subsection{1 总体思路}

本文研究方法的总体思路是: (1) 选取相关指标 评价不同乡镇生产、生活与生态功能的时空变化; (2) 以 $50 \mathrm{~m} \times 50 \mathrm{~m}$ 栅格为单元评价研究区“三生”空 间的适宜性; 3 “三生” 空间划分必须考虑不同单元 的乡村多功能时空变化, 同时又要以适宜性为基 础, 于是借鉴生态位中 “态”与 “势”理念, 把 2016 年 乡村多功能与第(2)步中的适宜性作为 “态”, 把第(1) 步中的多功能时空变化作为“势”, “势”与 “态”共同 得到基于乡村多功能的“三生” 空间适宜性; (4) 以第 (3)步中经多功能时空修正后的“三生”空间适宜性 为根据划分研究区 “三生”空间。总体方法思路见 图 1 , 具体方法设计详见后文。

文中多功能评价基于乡镇尺度, 而适宜性评价 则基于图斑尺度,并未把两者统一到同一尺度。直 接原因是: 首先乡村多功能评价指标很多只能停留 在乡镇尺度, 无法得到其图斑数值(表 1), 现有文献 最小评价单元只为乡镇级, 其次县域“三生”空间又 必须基于图斑尺度才有意义。这体现多尺度联合 的科学涵义, 即图斑划为哪一功能区不仅由其本身 属性决定, 还受上一层级单元影响, 即生态学与地 理学中尺度传递效应(邬建国, 2007)。 


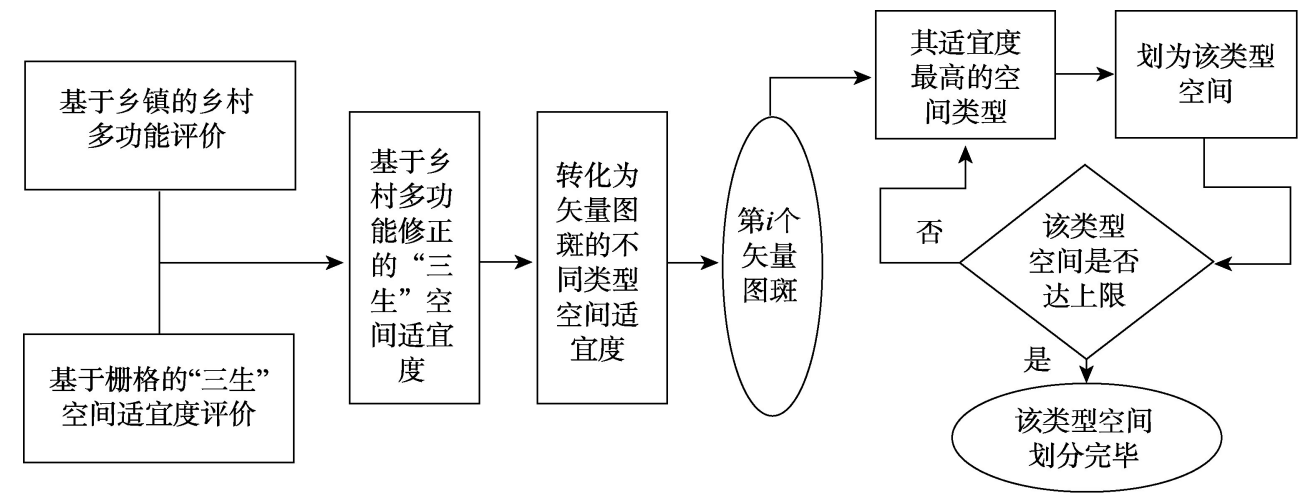

图 1 总体研究思路与方法

Fig.1 Framework of the research and methods

表 1 乡村多功能类型与评价指标

Tab.1 Types of rural multifunction and corresponding evaluation indicators

\begin{tabular}{|c|c|c|c|c|c|c|}
\hline \multicolumn{2}{|c|}{ 功能类型 } & 指标 & 权重 & 功能类型 & 指 标 & 权重 \\
\hline \multirow[t]{12}{*}{ 生产功能 } & 农业生产 & 农作物播种面积比重 & 0.074 & 生活功能 & 农民人均纯收人 & 0.051 \\
\hline & & 人均粮食总产量 & 0.065 & & 建成区人口占比 & 0.062 \\
\hline & & 人均耕地面积 & 0.074 & & 自来水普及率 & 0.011 \\
\hline & & 地均农业机械动力 & 0.025 & & 楼房比重 & 0.008 \\
\hline & & 农用地面积比重 & 0.055 & & 燃气普及率 & 0.007 \\
\hline & & 有效灌溉占耕地比重 & 0.034 & & 医疗机构床位数 & 0.021 \\
\hline & 非农业生产 & 固定资产投资 & 0.044 & & 在校学生数 & 0.041 \\
\hline & & 工业企业从业人员 & 0.035 & 生态功能 & 森林覆盖率 & 0.051 \\
\hline & & 企业税收总额 & 0.041 & & 水网密度 & 0.021 \\
\hline & & 财政收人 & 0.102 & & 生境质量 & 0.071 \\
\hline & & 企业个数 & 0.042 & & 人均生态服务价值 & 0.045 \\
\hline & & 外来从业人员 & 0.008 & & 风景旅游区面积占比 & 0.012 \\
\hline
\end{tabular}

\subsection{2 乡村多功能评价指标与方法}

乡村地域功能有不同分类, 已有详细综述 (刘 玉等, 2011)。多功能评价时功能类型划分有差异, 有学者以乡村振兴的 5 个维度划分乡村功能(陈秧 分等, 2018), 有些则划分为生态、农业、工业与社会 保障 4 大功能(李平星等, 2015), 还有些从生态服务 功能角度拓展乡村功能并展开评价 (张晓琳等, 2019)。乡村功能类型划分一方面应考虑社会经济 发展对各类功能的需求, 另一方面还要对接乡村战 略与空间重构的需求。本文借鉴任国平等(2018)、 洪惠坤等(2016)的做法, 把乡村地域一级功能划分 为生产、生活与生态 3 类, 又把生产功能划分为农业 生产与非农生产功能(徐凯等, 2019)。这是因为粮 食安全关系到国计民生, 外部条件不确定情况下必 须牢牢把饭碗端在自己手中。虽然城市边缘区乡 村休闲消费与保护等多功能价值凸显, 但要谨防非
农功能对农业功能的挤压。乡村多功能理论构建 者 Holmes(2006)曾指出乡村多功能转型的前提之 一是粮食产能过剩, 显然中国并非如此, 耕地保护 一直是中国基本国策,城市边缘区优质耕地的粮食 生产使命没有改变。具体表征指标与权重见表 1 。

权重用专家打分法确定,具体把类似文献中指 标权重发给 10 位高校专家作为参考借鉴, 经 2 轮打 分确定表 1 中权重。农业生产功能用人均粮食产 量、播种面积占比、农用地面积比重等 6 项指标表 征, 综合表示某单元农业生产能力; 非农生产主要 指乡镇的二三产业情况，本文用固定资产投资、企 业税收总额等 6 项指标表示,其中财政收人权重最 高, 为 0.102 , 外来从业人员数权重最小, 为 0.008 。 生活功能主要指提供给居民生活环境与水平的能 力, 总体上认为农民人均收人与城镇人口比率越 高, 则该能力越强, 于是从人均收人、医疗机构床位 
数等 7 项指标来量化, 其中建成区人口占比权重最 高, 为 0.062 。生态功能用森林覆盖率、生境质量等 5 项指标表征,其中生境质量采用环境保护部(2015) 方法测算, 不同类型用地生态服务价值当量采用李 金金(2013)的方法。表 1 中的评价指标多数是一种比 率或能力指标, 且全部是正向指标,需进行标准化, 之后用综合评价法可得到 2009年与 2016年研究区 乡镇尺度的乡村多功能水平与变化。

$$
\begin{gathered}
h_{i z r}=\frac{H_{i z r}-\min \left(H_{z r}\right)}{\max \left(H_{z r}\right)-\min \left(H_{z r}\right)} \\
M_{i z}=\sum_{r=1}^{R} w_{z r} \times h_{i z r}
\end{gathered}
$$

式中: $H_{i z r}$ 是第 $i$ 镇第 $z$ 个功能中第 $r$ 个指标的真实 值, $\max \left(H_{z r}\right)$ 与 $\min \left(H_{z r}\right)$ 则表示样本中该指标的最 大值与最小值; $h_{i z r}$ 是第 $i$ 镇第 $z$ 个功能中第 $r$ 个指 标的标准化值; $M_{i z}$ 是第 $i$ 个镇第 $z$ 个功能的得分; $w_{z r}$ 是 $z$ 个功能中第 $r$ 个指标权重; $R$ 为指标总数。

\subsection{3 “三生”空间适宜性评价方法}

关于 “三生”空间适宜性评价研究已较多(魏小 芳等, 2019; 张云路等, 2019), 本文以 $50 \mathrm{~m} \times 50 \mathrm{~m}$ 栅 格为空间单元, 因地制宜考虑城市边缘区乡村土地 利用的影响因素, 并把这些因素空间化, 之后在 ArcGIS 中的 Raster Calculator 分别对农业生产空 间、非农生产空间、生活空间与生态空间的适宜性 作叠加评价, 得到不同栅格对各类功能空间的适宜 度。具体评价因素与权重见表 2 , 同样权重用专家 打分法确定。

土地利用现状是指不同现状属性影响“三生” 空间适宜度, 如现状农用地更适宜于农业生产空
间,而城乡建设用地尤其城镇用地很难转变为农业 生产用地, 这主要由不同用地类型间转换成本决 定,这也体现了“三生”空间优化必须基于现状,不 能进行剧烈改变。因此该因素在全部类型空间适 宜度评价时权重都较大, 如现状城镇用地、风景旅 游用地必须给予其较高权重才能保证不被划人农 业生产空间, 工矿用地更宜于非农生产功能等, 不 同用地类型对 “三生”空间的相对适宜度系数参考 李金金(2013)的研究。农业生产空间适宜度从坡度、 土壤、土地利用现状等方面评价, 不同土壤类型总 其对农业适宜度不同, 与农村居民点距离主要考虑 耕作便利性。非农生产空间主要从是否适宜于产 业发展角度评价，包括坡度、土地利用现状、与城市 距离、与省级以上道路距离等, 充分考虑经济生产 对区位的要求,以便于要素对外交流,同时减少建 设经营成本。生活空间与非农生产空间适宜性的 要求差异主要体现在:一是土地利用现状中的工矿 用地、交通水利用地等更适宜于非农生产空间,而 村庄等则更适宜于生活空间，二是生活空间对公共 服务设施区位要求很高, 而非农生产空间对与道 路、城镇距离等区位更敏感。生态空间适宜度从生 态管控区、与水域距离等 3 个因素进行评价,其中对 一级生态管控、二级生态管控与非管控区分别赋值 $1 、 0.5 、 0.2$, 与水域距离越近, 越可能划为生态空间。

1.3.4 基于多功能评价的“三生”空间划定方法

基于图斑的“三生” 空间划定既要考虑图斑尺 度适宜性, 又要顾及镇级尺度的多功能评价, 需多 尺度联合决定图斑的功能区类型。上文分别评价 了研究区基于乡镇尺度的乡村多功能与基于栅格

表 2 “三生”空间适宜性评价影响因素与权重

\begin{tabular}{|c|c|c|c|c|c|c|c|c|}
\hline \multirow{2}{*}{ 影响因素 } & \multicolumn{2}{|c|}{ 农业生产空间 } & \multicolumn{2}{|c|}{ 非农生产空间 } & \multicolumn{2}{|c|}{ 生活空间 } & \multicolumn{2}{|c|}{ 生态空间 } \\
\hline & 评价因素 & 权重 & 评价因素 & 权重 & 评价因素 & 权重 & 评价因素 & 权重 \\
\hline 坡度 & $V$ & 0.2038 & $V$ & 0.0107 & $V$ & 0.0592 & & \\
\hline 土地利用现状 & V & 0.3621 & V & 0.3911 & V & 0.3152 & V & 0.4685 \\
\hline 土壤 & V & 0.1583 & & & & & & \\
\hline 地貌 & V & 0.0096 & V & 0.0531 & V & 0.0838 & & \\
\hline 与城市距离 & & & V & 0.1143 & V & 0.1697 & & \\
\hline 与镇距离 & & & V & 0.1464 & V & 0.1307 & & \\
\hline 与省级以上道路距离 & & & V & 0.1652 & & & & \\
\hline 与公共服务设施距离 & & & & & V & 0.1329 & & \\
\hline 生态管控区 & & & & & & & V & 0.3811 \\
\hline 与水域距离 & & & & & & & V & 0.1504 \\
\hline 与农村居民点距离 & V & 0.1545 & V & 0.1192 & V & 0.1085 & & \\
\hline
\end{tabular}

Tab.2 Suitability evaluation indicators and weights for the "production-living-ecological" space 
的“三生”空间适宜度，下文联合两者构建基于多功 能评价的“三生”空间划定方法。

第一步, 得到修正后对不同功能空间的适宜度 $S M_{i j z}$ :

$$
S M_{i j z}=S_{i j z}+M 2016_{i z}+9 \times \Delta M_{i z} / 7
$$

式中: $S_{i j z}$ 是 1.3 .3 小节中评价得到的第 $i$ 个镇第 $j$ 个 栅格对第 $z$ 类功能空间的适宜度; $M 2016_{i z}$ 是 2016 年 第 $i$ 个镇对第 $z$ 类功能大小; $\Delta M_{i z}$ 表示 2016 至 2009 年间不同镇不同功能的变化, 则 $9 \times \Delta M_{i z} / 7$ 表示目标 年 2025 年的功能变化量。 $S_{i j z}$ 与 $M 2016_{i z}$ 可看作生态 位中的“态”, $\Delta M_{i z}$ 则看作 “势”, 表示未来乡村多功 能的变化趋势。经计算可得到多功能修正后的空 间栅格对“三生”空间的适宜度。

第二步,把空间栅格转化为矢量图斑对 “三生” 空间的适宜度,示意图见图 2, 比如该图斑划分为 18 个完整或残缺栅格单元, 每个栅格有各自面积与对

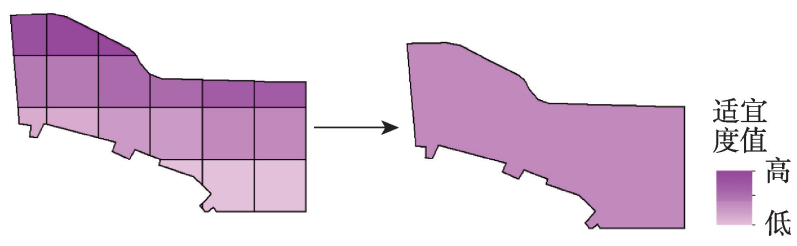

图 2 栅格空间适宜度转化为图斑适宜度的示意图

Fig.2 An illustration of the conversion from grid-level suitability to vector-level suitability

(a) 农业生产功能
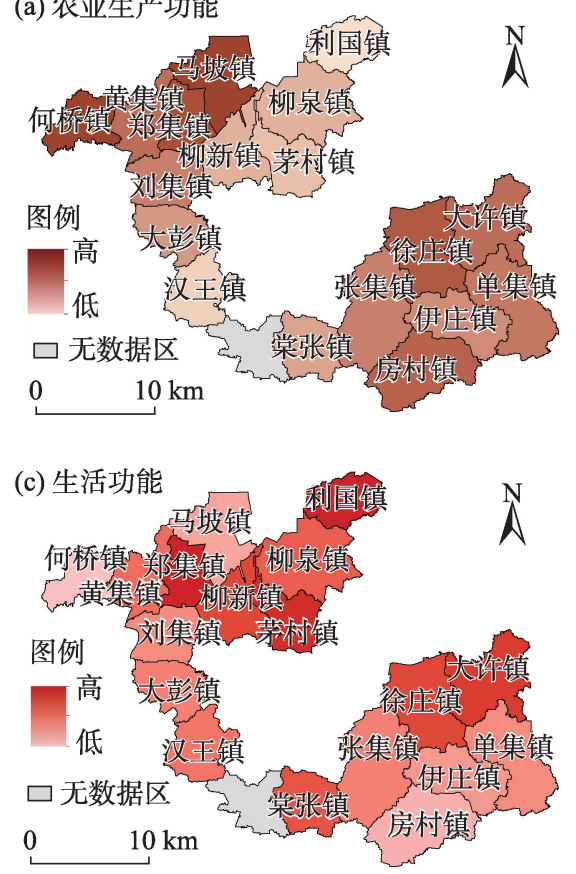

不同功能空间的适宜度,于是以面积比例为权重求 和得到该矢量图斑对各功能空间的适宜度,这步操 作经 ArcGIS 中属性的交叉分析, 再导人 Excel 中计 算,之后再按图斑编号连接到图斑属性表。

第三步,根据矢量图斑对不同类型功能空间的 适宜度, 在 ArcGIS 平台下用Python 语言构建一个简 单循环算法实现 “三生”空间划分, 即从第一个图斑 开始, 比较其对农业生产、非农生产、生活与生态空 间的适宜度, 将其划为适宜度最高的空间类型, 依次 循环, 直到某一类空间数量达到要求, 便把该类型 空间移除循环,循环结束即“三生”空间划定完毕。

\section{2 实证结果与分析}

\section{1 乡村多功能评价结果}

分别对 2009年与 2016 年铜山区乡村多功能进 行评价。图 3 是 2016年乡村多功能评价结果, 可发 现农业生产功能较突出是马坡镇、何桥镇与郑集镇 等,因为这些地区耕地质量高,是传统粮食产区, 不 仅人均粮食产量、人均耕地等指标高, 而且区内重 点打造优质稻麦示范区、智慧农业粮食产业园等, 同时农田整治与水利建设等集中在这些镇内, 进一 步提升其农业生产功能;而与市区接壤的茅村镇、 汉王镇等则农业生产功能较弱, 主要是因为非农经
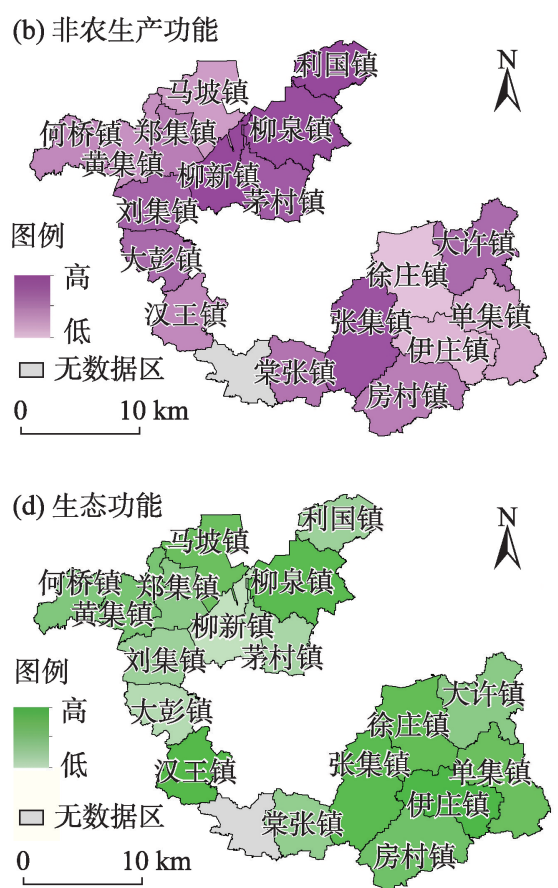

图 32016 年铜山区不同乡村功能地域分布

Fig.3 Spatial distribution of rural multifunction of Tongshan District, Xuzhou City, Jiangsu Province, 2016 
济进行扩散, 土地、人口与社会等就地城镇化, 导致 农业生产要素流失。非农生产功能主要集中在利 国镇、柳泉镇、柳新镇等铜山区北翼, 这些镇由于靠 近铁路货运站, 且坐拥京杭运河内陆码头, 交通运 输便利, 又有矿产资源优势, 如利国镇铁矿、柳泉镇 煤矿等,因此不仅特色工矿企业众多,而且积极发 展对外交通、仓储等功能, 更是市区产业功能承接 地, 成为城市外围发展的重要组团, 非农收人成为 农民收人主要来源, 因此非农生产功能突出。生活 功能较强的主要有郑集镇、徐庄镇、大许镇与利国 镇等, 由于这些镇经济实力较强, 镇区人口比例高, 因此公共服务与生活配套设施健全, 人居环境较 好, 同时教育医疗资源丰富, 因此生活功能较强, 是 未来人口集聚的重点小城镇; 而何桥镇与房村镇等 则由于经济水平低, 基础设施与公共服务设施相对 员乏, 故生活功能较弱。生态功能较强镇主要分布 在伊庄镇、张集镇、徐庄镇与汉王镇等, 这主要因为 吕梁风景区一一徐州市后花园位于这些镇内, 区内 森林覆盖率达 $88 \%$, 植被众多, 水域密集, 物种多 样, 生态服务价值较高, 不仅具有空气净化、生物多 样性保护等功能, 更有休闲娱乐、旅游度假等功能, 汉王镇由于地形起伏, 具有丰富的生态资源, 是江 苏省宜居生态乡镇建设典范, 被评为中国绿色名 镇, 因此生态功能突出。

由表 3 可发现,2009-2016年间农业生产功能 减小的有 3 个镇, 分别是位于城市周边的柳新镇、棠 张镇与黄集镇, 由于紧邻城市, 城市扩张侵占乡村 空间, 土地、劳动力等农业要素易流失, 与之对应的 是非农生产功能提升幅度较大, 这从侧面反映徐州 城市扩张方向是正北与东南。非农生产功能提升 幅度最大的是利国镇, 这可能因为其工矿企业转型 成功, 企业个数与财政收人等都有大幅提升, 只有
汉王镇与徐庄镇的非农生产功能在下降, 虽然二者 紧靠中心城区, 但汉王镇向绿色生态转型, 徐庄镇 受开发区的“虹吸效应”,因此以工业为代表的非农 生产功能在减小。生活功能普遍在提升, 说明乡村 生活环境条件在持续改善, 人口持续向镇区集中。 但期间生态功能却在普遍下降, 只有汉王镇因打造 绿色名镇,生态功能在提升,说明城市边缘区社会 经济活动对生态系统扰动性增强, 导致生态服务 功能受侵蚀。

进一步研究发现, 不但各功能时空分布表现出 一定规律, 而且其相互之间的关系也有一定规律。 农业生产功能与非农生产功能表现出高度互斥, 即 农业生产功能高则非农生产功能低, 反之亦然, 这 主要因为两者是竞争关系, 非农生产意味占用农 地, 吸纳农业人口, 农业比较收益低, 因此农业生产 功能要素流失, 不管是其空间分异还是时间变化 上, 二者都表现出显著竞争互斥性。非农生产功能 与生活功能表现出正相关, 即协同关系, 这主要因 为非农生产功能强则居民与财政收人高, 于是具有 改善居住条件与农村人居环境的物质基础。生态 功能具有明显空间异质性, 即很大程度上由生态资 源空间分布决定,虽与农业生产功能表现出空间协 同,农业生产功能大的镇生态功能也较高, 但这种 协同关系不明显。

\section{2 “三生”空间划定结果}

图 4 是经乡村多功能修正后的“三生”空间适宜 度,正是据其划定“三生”空间。农业生产适宜度较 高空间主要分布在西北部的马坡镇、郑集镇与东部 大许镇、徐庄镇; 非农生产适宜度较高空间主要分 布在茅村镇、柳新镇与利国镇; 生活适宜度较高空 间则主要分布郑集镇、茅村镇与利国镇等;生态适 宜度较高空间主要分布在东南部的吕梁风景区与

表3 2009-2019年间铜山区不同镇乡村多功能的相对变化

Tab.3 Relative change of rural multifunction of different towns in Tongshan District of Xuzhou City, 2009-2019

\begin{tabular}{cccccrrrrr}
\hline 功能 & 大彭镇 & 大许镇 & 单集镇 & 房村镇 & 汉王镇 & 何桥镇 & 黄集镇 & 利国镇 & 刘集镇 \\
\hline 农业生产 & 0.0413 & 0.0066 & 0.0271 & 0.0043 & 0.0023 & 0.0403 & -0.0079 & 0.0033 & 0.0239 \\
非农生产 & 0.0427 & 0.0282 & 0.0132 & 0.0306 & -0.0011 & 0.0308 & 0.0152 & 0.1124 & 0.0244 \\
生活功能 & 0.0355 & 0.0671 & 0.0320 & 0.0421 & 0.0304 & 0.0414 & 0.0564 & 0.0719 & 0.0313 \\
生态功能 & -0.0026 & -0.0006 & -0.0007 & -0.0012 & 0.0032 & -0.0027 & -0.0013 & -0.0027 & 0.0006 \\
\hline \hline 功能 & 柳泉镇 & 柳新镇 & 马坡镇 & 茅村镇 & 棠张镇 & 徐庄镇 & 伊庄镇 & 张集镇 & 郑集镇 \\
\hline 农业生产 & 0.0242 & -0.0060 & 0.0093 & 0.0319 & -0.0084 & 0.0182 & 0.0018 & 0.0072 & 0.0234 \\
非农生产 & 0.0631 & 0.1029 & 0.0168 & 0.0648 & 0.0199 & -0.0028 & 0.0023 & 0.0580 & 0.0243 \\
生活功能 & 0.0237 & 0.0300 & 0.0279 & 0.0828 & 0.0054 & 0.0467 & 0.0295 & 0.0373 & 0.0759 \\
生态功能 & -0.0092 & -0.0046 & -0.0090 & -0.0010 & -0.0004 & -0.0006 & -0.0049 & -0.0042 & -0.0009 \\
\hline
\end{tabular}


北部微山湖岸区。

图 5 是用本文所构建方法划定的研究区“三生” 空间, 按上级主体功能区划规定农业、非农生产、生 活与生态空间数量占比分别为 $56.13: 7.32: 14.4$ :
22.15 , 用本文所构建方法将其配置至图斑尺度。结 果发现,农业生产空间主要分布在西北部与西部, 且与城市距离越远分布越集中, 这是因为非农生产 对其挤压越小,而城市周边农业空间受其他空间分

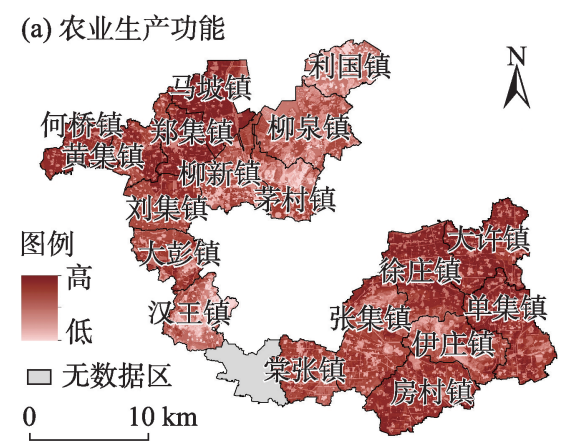

(b) 非农生产功能

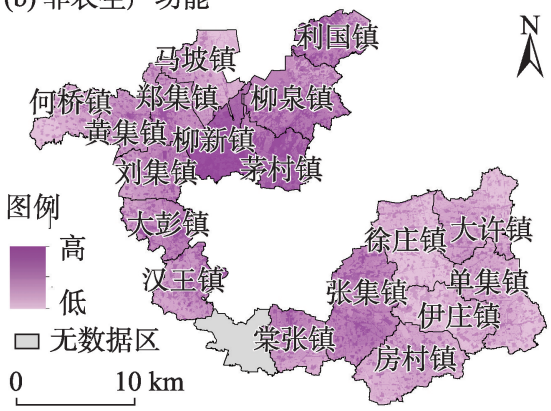

(c) 生活功能

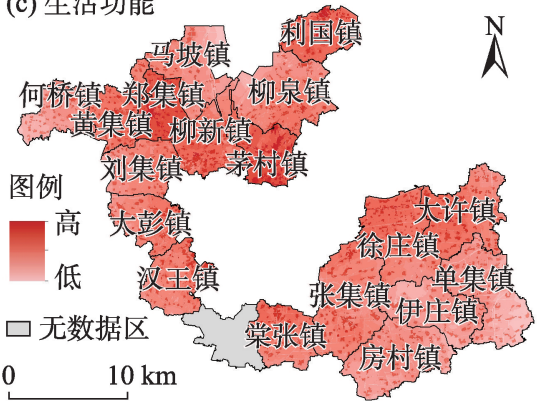

(d) 生态功能

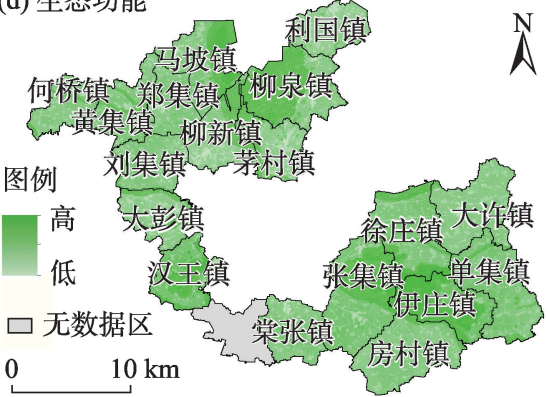

图 4 经乡村多功能修正后的三生空间适宜度评价结果

Fig.4 Vector-level spatial suitability of "production-living-ecological" space with modified rural multifunction

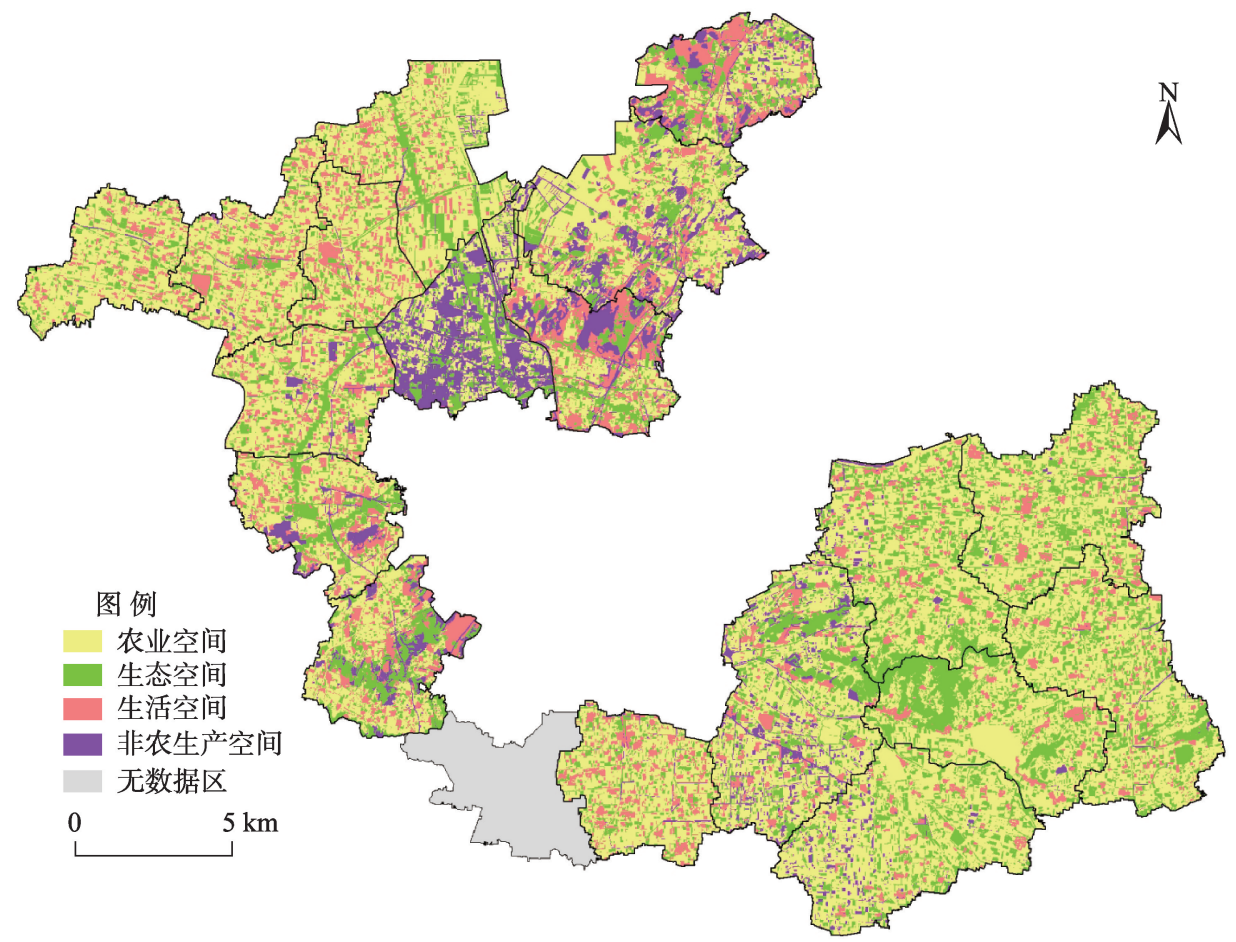

图 5 基于乡村多功能评价的“三生”空间划分

Fig.5 Delineation of "production-living-ecological" space based on rural multifunction evaluation 
割则较为细碎。非农生产空间则主要分布在北部 的柳泉镇、柳新镇与利国镇等, 表现出明显空间集 聚性,这主要因为该地区本身工矿企业多, 又有高 速路出口、铁路货运站、京杭大运河码头等基础设 施,加之非农生产活动因 “马歇尔效应”其本身有空 间集聚特征,于是导致该类空间集聚; 同时发现东 南部沿机场线亦有零星非农生产空间。生态空间 主要沿河道分布, 同时吕梁风景区与汉王镇是生态 空间主要分布地, 总体上呈东多西少的布局, 尤其 东部乡镇生态空间密度较大, 这可能因为东部地区 生态基础较好, 交通便利, 是徐州市区周末休闲度 假的主要去处。生活空间则主要分布在城镇所在 地与城市周边, 同时农村居民点是生活空间重要组 分, 但东部地区生活空间组团相对西北较大, 这主 要因为西北部主要以农业生产为主, 因此对耕作便 利性要求较高, 于是生活空间组团面积小, 但密度 大。各类空间有较好兼容性, 并没表现出高度集聚 性, 主要是因为该研究中 “三生” 空间划分基于图斑 尺度, 充分考虑土地利用现实情况, 且事实上, 按照 景观功能的共生理论(邬建国, 2007), 各类空间确需 相互兼容,该级尺度的“三生”空间划分是未来空间 规划主要内容。

\section{3 结论与讨论}

\section{1 结论}

中国现阶段城镇化水平下城市边缘区乡村多 元价值凸显, 迫切需以乡村多功能理论划定 “三生” 空间,进行空间重构, 为空间规划编制提供科学借 鉴, 为多元价值挖掘与培育提供空间基础, 促进地 区转型发展。本文首先从生产、生活与生态功能方 面评价城市边缘区乡村多功能时空变化; 其次基于 栅格尺度选择相关影响因素进行“三生”空间适宜 性评价, 并用多功能对其进行修正, 得到基于乡村 多功能的 “三生” 空间适宜性评价结果; 最后据此设 计算法划分“三生”空间,主要研究结论有:

(1) 现阶段城市边缘区乡村休闲娱乐、观光农 业等功能显现, 应以乡村多功能理论对其进行空间 重构,划定“三生”空间, 促进转型发展, 扭转该地区 混杂、衰退局面。

(2) 铜山区非农生产与生活功能主要分布在与 中心城区较近地区, 与基础设施和公共服务设施分 布表现出正相关性,农业空间主要分布在中心城区
外围,生态功能则表现出高度空间异质性,农业、非 农生产与生活功能在提升, 而生态功能则普遍 下降。

(3) 县域 “三生” 空间划分需要多尺度联合, 既 要考虑乡镇尺度多功能差异, 还要体现图斑尺度适 宜性与土地利用现状, 才能为空间规划提供有意义 的借鉴。

(4) 本文提出的基于乡村多功能评价的 “三生” 空间划定法,不仅以乡村多功能理论为指导进行空 间重构, 还考虑了图斑尺度的生物物理因素, 有合 理性与可行性,可为空间规划提供科学依据。

\section{2 讨论}

乡村多功能理论可为目前中国城乡融合发展、 乡村振兴与转型等提供重要理论支持, 应切实用于 指导相关规划编制与体制机制构建 (龙花楼等, 2018)。但其毕竟产生于高度城镇化且资源禀赋丰 富的西方国家,这些外部条件在中国发生了变化, 因此多功能形成与类型划分时要体现中国发展阶 段等情况差异,甚至要体现空间地域差异。此外, 空间规划目前是区域土地利用与社会经济活动的 根本部署,应加强多功能理论用于空间管制实践的 探索, 尤其县域规划细化到图斑, 如何联合多尺度 共同决定图斑功能类型值得进一步研究, 本文提出 的基于乡村多功能的 “三生” 空间划定法有待进一 步检验。最后用多功能理论指导空间重构时,如何 厘清政府与市场边界有待深人探索,政府主要是打 破空间“粘性”,制定空间框架,构建有利于要素自 由流动的体制机制,而其他则应交由市场实现。

\section{参考文献(References)}

陈秧分, 黄修杰, 王丽娟. 2018. 多功能理论视角下的中国乡 村振兴与评估 [J]. 中国农业资源与区划, 39(6): 201-209. [Chen Y F, Huang X J, Wang L J. 2018. China's rural revitalization and its evaluation from the perspective of multifunctional theory. Chinese Journal of Agricultural Resources and Regional Planning, 39(6): 201-209. ]

房艳刚, 刘继生. 2015. 基于多功能理论的中国乡村发展多 元化探讨: 超越“现代化”发展范式 [J]. 地理学报, 70(2): 257-270. [Fang Y G, Liu J S. 2015. Diversified agriculture and rural development in China based on multifunction theory: Beyond modernization paradigm. Acta Geographica Sinica, 70(2): 257-270. ]

戈大专, 龙花楼, 李裕瑞, 等. 2018. 城镇化进程中我国粮食 生产系统多功能转型时空格局研究: 以黄淮海地区为例 
[J]. 经济地理, 38(4): 147-156,182. [Ge D Z, Long H L, Li Y R, et al. 2018. The spatio-temporal pattern of multifunctional transformation of China's grain production system in the process of urbanization: The case of Huang-Huai-Hai Plain. Economic Geography, 38(4): 147-156, 182. ]

洪惠坤. 2016. “三生”功能协调下的重庆市乡村空间优化研 究 [D]. 重庆: 西南大学. [Hong H K. 2016. Research on the rural space optimization of Chongqing City from a coordination of "Sansheng" function. Chongqing, China: Southwest University. ]

洪惠坤, 廖和平, 李涛, 等. 2016. 基于熵值法和 Dagum 基尼 系数分解的乡村空间功能时空演变分析 [J]. 农业工程学 报, 32(10): 240-248. [Hong H K, Liao H P, Li T, et al. 2016. Analysis of spatio-temporal patterns of rural space function based on entropy value method and Dagum Gini coefficient. Transactions of the CSAE, 32(10): 240-248. ]

环境保护部. 2015. HJ/T 192-2015 生态环境状况评价技术 规范 [S]. 北京: 中国环境科学出版社. [People's Republic of China Environmental Protection Department. 2015. HJ/ T 192-2015 technical criterion for ecosystem status evaluation. Beijing, China: China Environmental Science Press. ]

黄金川, 林浩曦, 漆潇潇. 2017. 面向国土空间优化的三生空 间研究进展 [J]. 地理科学进展, 36(3): 378-391. [Huang J C, Lin H X, Qi X X. 2017. A literature review on optimization of spatial development pattern based on ecologicalproduction- living space. Progress in Geography, 36(3): 378-391. ]

李广东, 方创琳. 2016. 城市生态-生产-生活空间功能定量 识别与分析 [J]. 地理学报, 71(1): 49-65. [Li G D, Fang C L. 2016. Quantitative function identification and analysis of urban ecological- production- living spaces. Acta Geographica Sinica, 71(1): 49-65. ]

李平星, 陈诚, 陈江龙. 2015. 乡村地域多功能时空格局演变 及影响因素研究: 以江苏省为例 [J]. 地理科学, 35(7): 845-851. [Li P X, Chen C, Chen J L. 2015. Temporal evolution and spatial differentiation of rural territorial multifunctions and the influencing factors: The case of Jiangsu Province. Scientia Geographica Sinica, 35(7): 845-851. ] 李平星, 陈雯, 孙伟. 2014. 经济发达地区乡村地域多功能空 间分异及影响因素: 以江苏省为例 [J]. 地理学报, 69(6): 797-807. [Li P X, Chen W, Sun W. 2014. Spatial differentiation and influencing factors of rural territorial multifunctions in developed regions: A case study of Jiangsu Province. Acta Geographica Sinica, 69(6): 797-807. ]

李金金. 2013. 基于不确定性的区域土地利用结构与布局优化
研究 [D]. 南京: 南京农业大学. [Li X. 2013. Study on optimize of regional land use structure and layout based on the uncertainty. Nanjing, China: Nanjing Agricultural University. ]

李智, 范琳芸, 张小林. 2017. 基于村域的乡村多功能类型划 分及评价研究: 以江苏省金坛市为例 $[\mathrm{J}]$. 长江流域资源 与环境, 26(3): 359-367. [Li Z, Fan L Y, Zhang X L. 2017. Types division of rural multifunctions and their evaluation on village scale: A case of Jintan City, Jiangsu Province. Resources and Environment in the Yangtze Basin, 26(3): 359-367. ]

林娇. 2018. 川西高原地区的“三生”空间动态变化与优化研 究: 以炉霍县为例 [D]. 成都: 四川师范大学. [Lin J. 2018. The research on the dynamic changes and optimization of "Production- Living- Ecological" space in western Sichuan Plateau: Take Luhuo County as an example. Chengdu, China: Sichuang Normal University. ]

刘玉, 刘彦随. 2012. 乡村地域多功能的研究进展与展望 [J]. 中国人口・资源与环境, 22(10): 164-169. [Liu Y, Liu Y S. 2012. Progress and prospect in the study of rural region multifunctions. China Population, Resources and Environment, 22(10): 164-169. ]

刘玉, 刘彦随, 郭丽英. 2011. 乡村地域多功能的内涵及其政 策启示 [J]. 人文地理, 26(6): 103-106, 132. [Liu Y, Liu Y S, Guo L Y. 2011. Connotations of rural regional multifunction and its policy implications in China. Human Geography, 26(6): 103-106, 132 . ]

刘祖云, 刘传俊. 2018. 后生产主义乡村: 乡村振兴的一个理 论视角 $[\mathrm{J}]$. 中国农村观察, (5): 2-13. [Liu Z Y, Liu C J. 2018. The post-productivist countryside: A theoretical perspective of rural revitalization. China Rural Survey, (5): 213. ]

龙花楼, 屠爽爽. 2018. 乡村重构的理论认知 [J]. 地理科学进 展, 37(5): 581-590. [Long H L, Tu S S. 2018. Theoretical thinking of rural restructuring. Progress in Geography, 37 (5): 581-590. ]

乔家君, 马玉玲. 2016. 城乡界面的经济效应 [J]. 经济地理, 36(9): 1-9. [Qiao J J, Ma Y L. 2016. Economic effects of urban and rural interfaces. Economic Geography, 36(9): 1-9. ] 任国平, 刘黎明, 孙锦, 等. 2018. 基于 GRA 和 TOPSIS 模型的 都市郊区乡村景观多功能定位 [J]. 地理研究, 37(2): 263280. [Ren G P, Liu L M, Sun J, et al. 2018. Multifunction orientation of rural landscape in metropolitan suburbs based on GRA and TOPSIS models. Geographical Research, 37(2): 263-280. ] 
宋志军, 刘黎明. 2012. 1988 年以来北京郊区城乡一体化进 程及启示 [J]. 地理科学进展, 31(8): 1071-1079. [Song Z J, Liu L M. 2012. The process and enlightenment of urbanrural integration in Beijing since 1988. Progress in Geography, 31(8): 1071-1079. ]

王婕, 魏朝富, 刘卫平, 等. 2018. 基于 “三生”视角的山地丘 陵区土地整治功能分区: 以重庆市綦江区为例 [J]. 地域 研究与开发, 37(3): 155-159, 171. [Wang J, Wei C F, Liu W P, et al. 2018. Land consolidation zoning in hilly areas of Southwest China based on the function of production, living and ecology: A case study of Qijiang District of Chongqing City. Areal Research and Development, 37(3): 155-159, 171. ]

魏小芳, 赵宇变, 李秀涁, 等. 2019. 基于 “三生功能”的长江 上游城市群国土空间特征及其优化 [J]. 长江流域资源与 环境, 28(5): 1070-1079. [Wei X F, Zhao Y L, Li X B, et al. 2019. Characteristics and optimization of geographical space in urban agglomeration in the upper reaches of the Yangtze River based on the function of "Production-Living-Ecological". Resources and Environment in the Yangtze Basin, 28(5): 1070-1079. ]

邬建国. 2007. 景观生态学: 格局、过程、尺度与等级 [M]. 2 版. 北京: 高等教育出版社: 17-19. [Wu J G. 2007. Landscape ecology: Pattern, process, scale and hierarchy. 2nd edition. Beijing, China: Higher Education Press: 17-19. ]

徐凯, 房艳刚. 2019. 乡村地域多功能空间分异特征及类型 识别: 以辽宁省 78 个区县为例 [J]. 地理研究, 38(3): 482495. [Xu K, Fang Y G. 2019. Spatial differentiation and type identification of rural territorial multi-functions in Liaoning Province. Geographical Research, 38(3): 482-495. ]

杨俊, 郭丽兰, 李争. 2018. 基于空间功能值的矿粮复合区三 生空间重构 [J]. 农业工程学报, 34(24): 247-255. [Yang J, Guo L L, Li Z. 2018. Reconstruction of living, production and ecological space based on spatial functional value in mine-grain mixed zone. Transactions of the CSAE, 34(24): 247-255. ]

张晓琳, 金晓斌, 范业婷, 等. 2019.1995-2015 年江苏省土地 利用功能转型特征及其协调性分析 [J]. 自然资源学报, 34(4): 689-706. [Zhang X L, Jin X B, Fan Y T, et al. 2019. Spatial-temporal characteristics and coordination status of the land use function transition in Jiangsu Province from 1995 to 2015. Journal of Natural Resources, 34(4): 689706. ]

张英男, 龙花楼, 马历, 等. 2019. 城乡关系研究进展及其对 乡村振兴的启示 [J]. 地理研究, 38(3): 578-594. [Zhang Y N, Long H L, Ma L, et al. 2019. Research progress of urban-rural relations and its implications for rural revitalization. Geographical Research, 38(3): 578-594. ]

张云路, 李雄, 孙松林. 2019. 基于“三生”空间协调的乡村空 间适宜性评价与优化: 以雄安新区北沙口乡为例 [J]. 城 市发展研究, 26(1): 116-124. [Zhang Y L, Li X, Sun S L. 2019. Evaluation and optimization of rural space suitability based on "the production, living and ecological space coordination": Take Beishakou Township, the Xiongan New Area as an example. Urban Development Studies, 26(1): 116-124. ]

Holmes J. 2006. Impulses towards a multifunctional transition in rural Australia: Gaps in the research agenda [J]. Journal of Rural Studies, 22: 142-160.

Pyror R J. 1968. Defining the rural urban fringe [J]. Social Forces, 47: 202-15.

Stola W. 1986. The functional classification of rural areas in the mountain regions of Poland [J]. Geographia Polonica, 52: $235-248$.

Wilson G A. 2001. From productivism to post-productivism and back again: Exploring the (un)changed natural and mental landscapes of European agriculture [J]. Transactions of the Institute of British Geographers, 26: 77-102. 


\title{
Delineation of "production-living-ecological" space for urban fringe based on rural multifunction evaluation
}

\author{
MA Xiaodong ${ }^{1}$, LI Xin ${ }^{1 *}$, HU Rui ${ }^{1}$, KHUONG Manh $\mathrm{Ha}^{2}$ \\ (1. School of Geography, Geomatics \& Planning, Jiangsu Normal University, Xuzhou 221116, Jiangsu, China; \\ 2. School of Land, Resources \& Environment, Bacgiang Agriculture and Forestry University, Bacgiang 0084240, Vietnam)
}

\begin{abstract}
Rural multifunctional values in urban fringes are prominent at the current stage of urbanization in China. Therefore, it is urgent to delineate "production-living-ecological" space using the rural multifunction theory in order to carry out spatial reconstruction. This study developed a comprehensive method for delineating the "production- living- ecological" space in urban fringe based on rural multifunction evaluation, taking Tongshan District of Xuzhou City for empirical research. First, the spatial and temporal changes of rural multifunctions were evaluated from the aspects of production, living, and ecological functions. Second, suitability evaluation for "production-living-ecological" space was carried out at the grid scale, and then, the rural multifunctional "production-living-ecological" space suitability evaluation result was attained. Finally, the "production- living- ecological" space was delineated. The study revealed that: 1) With the overwhelming development of rural recreation and sightseeing agriculture in urban fringe, the application of rural multifunction theory to the reconstruction of multifunctional space can promote development transition. 2) Non-agricultural production function and living function are mainly distributed in the suburbs surrounding the main urban area, while agricultural production function is mainly distributed in the outer suburbs, and ecological function shows clear spatial heterogeneity. Agricultural, non-agricultural production, and living functions are improving, while ecological function is declining. 3) "Production-living-ecological" space delineation at county level needs multiscale combination, not only considering the multifunctional differences at the township scale, but also accounting for suitability at the vector or grid level. The proposed method of delineating "production-livingecological" space based on rural multifunctional evaluation can provide a scientific basis for spatial planning.
\end{abstract}

Keywords: rural multifunction; urban fringe; "production-living-ecological" space; Tongshan District of Xuzhou in Jiangsu Province 